\title{
A 3-D Model of a Perennial Ryegrass Primary Cell Wall and Its Enzymatic Degradation
}

\author{
Indrakumar Vetharaniam ${ }^{1, *}$, William J. Kelly ${ }^{2}$, Graeme T. Attwood ${ }^{2}$ and Philip J. Harris ${ }^{3}$ \\ 1 AgResearch Limited, Ruakura Research Centre, Private Bag 3123, Hamilton 3240, New Zealand \\ 2 AgResearch Limited, Grasslands Research Centre, Private Bag 11008, Palmerston North 4442, \\ New Zealand; E-Mails: bill.kelly@agresearch.co.nz (W.J.K.); \\ graeme.attwood@agresearch.co.nz (G.T.A.) \\ 3 School of Biological Sciences, The University of Auckland, Private Bag 92019, Auckland 1142, \\ New Zealand; E-Mail: p.harris@auckland.ac.nz \\ * Author to whom correspondence should be addressed; \\ E-Mail: kumar.vetharaniam@agresearch.co.nz; Tel.: +64-7-838-5314; Fax: +64-7-838-5012.
}

Received: 23 December 2013; in revised form: 2 April 2014 / Accepted: 17 April 2014 /

Published: 5 May 2014

\begin{abstract}
We have developed a novel 3-D, agent-based model of cell-wall digestion to improve our understanding of ruminal cell-wall digestion. It offers a capability to study cell walls and their enzymatic modification, by providing a representation of cellulose microfibrils and non-cellulosic polysaccharides and by simulating their spatial and catalytic interactions with enzymes. One can vary cell-wall composition and the types and numbers of enzyme molecules, allowing the model to be applied to a range of systems where cell walls are degraded and to the modification of cell walls by endogenous enzymes. As a proof of principle, we have modelled the wall of a mesophyll cell from the leaf of perennial ryegrass and then simulated its enzymatic degradation. This is a primary, non-lignified cell wall and the model includes cellulose, hemicelluloses (glucuronoarabinoxylans, 1,$3 ; 1,4-\beta$ glucans, and xyloglucans) and pectin. These polymers are represented at the level of constituent monosaccharides, and assembled to form a 3-D, meso-scale representation of the molecular structure of the cell wall. The composition of the cell wall can be parameterised to represent different walls in different cell types and taxa. The model can contain arbitrary combinations of different enzymes. It simulates their random diffusion through the polymer networks taking collisions into account, allowing steric hindrance from cell-wall polymers to be modelled. Steric considerations are included when target bonds are encountered, and breakdown products resulting from enzymatic activity are predicted.
\end{abstract}


Keywords: plant cell wall; lignocellulose digestion; enzymatic degradation; enzymes; perennial ryegrass (Lolium perenne); rumen; fermentation; agent-based modelling

\section{Introduction}

The reticulo-rumen (more commonly known as the rumen) comprises the first two digestive compartments in the ruminant. It serves as a fermentation chamber in which the cell walls of plants (PCW) are converted into microbial biomass and end products that nourish the animal $[1,2]$. Improving rumen efficiency promises gains in both animal productivity and mitigating environmental impact from farming $[1,3]$. Understanding the physical disintegration of PCWs and the underlying enzymatic processes is vital to achieve this.

Two major groups of PCWs are recognized: primary walls which are formed as the cells are still enlarging, and secondary walls which are deposited on the primary wall of some cell types after the cells have stopped enlarging [4-6]. Both primary and secondary walls have similar basic structures consisting of cellulose microfibrils (CMFs) embedded in a matrix of other polysaccharides (hemicelluloses and pectin). Fully developed secondary walls and their underlying primary walls often also contain the aromatic polymer lignin which provides resistance to enzymatic attack [7] and the general term lignocellulose is often used $[3,8]$. Cellulose molecules consist of long unbranched chains of $(1,4)$-linked $\beta$-glucosyl residues and are aligned in parallel to form partly crystalline CMFs, which are quite resistant to enzymatic attack [6,9-11]. However, the compositions of the matrix polysaccharides are often quite different in primary and secondary walls within an individual plant. Moreover, these compositions also vary among different plant groups (taxa).

Perennial ryegrass (Lolium perenne L.) is a major component of the diet of pastoral ruminants and in this paper we focus on the primary (non-lignified) PCW of grasses, in which the principal matrix polysaccharide is usually the hemicellulose glucuronoarabinoxylan (GAX). GAXs have a backbone of $(1,4)$-linked $\beta$-xylosyl residues and side branches, mostly of single arabinosyl and glucuronic acid (or 4-O-methyl glucuronic acid) residues with ferulic acid being esterified to some of the arabinosyl residues $[6,9,10,12]$. Another family of hemicelluloses the $(1,3 ; 1,4)$ - $\beta$-glucans occur in variable proportions. These consist of unbranched chains of $(1,3)$-linked cellotriosyl or cellotetraosyl residues [4]. Less than $\sim 10 \%$ (by weight) of these polysaccharides contain longer blocks of up to $\sim 20$ adjacent $(1,4)$-linked $\beta$-glucosyl residues $[13,14]$. Small proportions of pectic polysaccharides and xyloglucans are also present.

Theoretical models have been proposed for the architecture of grass primary walls $[5,6,15]$. The most common are referred to as "tethered or sticky network models" and involve two co-extensive polymer networks. In the first network the main bridging molecules are considered to be GAXs with low degrees of substitution (i.e., carrying few side chains) which may hydrogen bond to the surfaces of adjacent CMFs. Some of the $(1,3 ; 1,4)-\beta$-glucans and xyloglucans may also hydrogen bond to the surfaces of CMFs and are included in this network. More highly substituted GAXs are considered to be the main components of the second polymer network, with contributions from pectins and perhaps $(1,3 ; 1,4)$ - $\beta$-glucans. GAXs in both networks may form cross links with one another by the 
coupling of ester-linked ferulic acids on adjacent molecules forming a range structurally different diferulates [16,17].

Microbial degradation of plant matter involves the sequential and synergistic action of communities of microbes whose ecology is highly responsive to their substrate [18]. In the rumen these communities are dominated by anaerobic bacteria [2,19] which secrete a suite of different enzymes such as cellulases, which include endo- and exo-glucanases (including cellobiohydrolases), cellobiases, endo- and exo-xylanases, xylosidases, $\alpha$-arabinofuranosidases, feruloyl esterases, glucuronidases, pectin lysases, and polygalacturonases. These enzymes and the bacteria that secrete them have been reviewed elsewhere [3,20-23]. Some of these enzymes are components of multi-enzyme complexes, known as cellulosomes, which often occur on the outer surfaces of bacteria [24]. The relative importance of these enzymes and how they interact are yet to be fully elucidated, as are the ecological factors governing the interactions and competitiveness of microbial species in the rumen. Knowledge of this is integral to understanding the fermentation process. However, the interactions involved have a complex interdependence that cannot be adequately understood by experiment alone, but rather requires a quantitative and integrative approach to link experimental data.

Mathematical modelling of rumen fermentation has typically characterised the diet in terms of broad chemical constituents and applied empirically measured kinetics and fermentation stoichiometries to predict digestion rates and end products. Reviewing these models is outside the scope of this paper, and evaluations can be found in the literature [25-28]. Modelling of fermentation in bioreactors has the potential to inform modelling of rumen function and has focussed most significantly on cellulose hydrolysis using classical mathematical approaches, both currently [29-34] and historically [35].

Researchers have increasingly turned to computer simulation, because the spatial and chemical complexities involved are intractable with traditional approaches. 3-D computer simulation has been used for detailed modelling at the atomic level, from the structure of molecules and crystals through to protein folding [36-40]. Of particular interest is computer simulation to understand the properties of lignin [41], and to model the CMF [42] and the interactions during the dyeing of cellulose [43]. Developments in the simulation of crystalline cellulose and its enzymatic degradation (ranging from the atomic level through to the mesoscale level) have recently been surveyed [44,45]. Subsequently mesoscale models simulating the enzymatic hydrolysis of crystalline cellulose have been published, by Warden et al. [46] who used a 3-D cellular automaton and by Asztalos et al. [47] who used a stochastic, 2-D grid-based approach. We consider it imperative that models of cell-wall digestion represent the entire cell wall, rather than just cellulose, if enzymatic degradation of cell walls is to be properly understood. Kha et al. [48] developed software which represents CMFs and hemicelluloses as beams, with defined mechanical and dimensional properties, that are linked to form a 3-D structure. This approach allowed the mechanical properties of the PCW to be predicted via finite element analysis, and has been extended to account for the strength of biochemical interactions between CMFs and hemicelluloses [49]. However, this approach lacks a representation of the molecular arrangement of the plant polymers and the complexity of their spatial structures, both of which are important when considering enzymatic effects. Consequently we have developed a 3-D model that represents the spatial arrangement of polymers forming the non-lignified, primary wall of a specific cell type (a mesophyll cell) in the leaf of perennial ryegrass (Lolium perenne), and contains enzymes which diffuse randomly and cleave bonds in the polymer network. This model will provide a basis for 
incorporating the gene, enzyme and microbial population data from rumen microbial genome projects, to investigate the extent to which components of ruminal cell-wall digestion affect each other, and to predict the sensitivity of the digestion system to changes in individual components and inputs. This is fundamental to understanding ruminal processes and manipulating them to maximise efficiency.

\section{Method}

We used an agent-based approach, which has the potential to reveal unexpected emergent behaviour [50]. Although agent-based modelling is usually associated with social science contexts using "intelligent" agents [50], it has application in the biological sciences [51], and has been used to model microbes and biofilm formation [52,53] and the immune system [54]. The model used an object-oriented approach implemented in $\mathrm{C}++$. The 'newmat' vector and matrix library for $\mathrm{C}++$ [55] was used for representing 3-D quantities, and the freeglut 2.8.0 library [56] was used to graphically represent individual molecules (monosaccharides, including uronic acids, and enzymes) in the simulation.

Separate classes were written for celluloses, GAXs, xyloglucans, $(1,3 ; 1,4)$ - $\beta$-glucans, ferulic acid dimers (diferulic acids), pectins and enzymes. Lengths were defined in terms of the radius of glucose (assuming a spherical glucose molecule), which we found more convenient to deal with than angstroms or nanometres. All monosaccharides, including uronic acids, and enzymes were represented as spheres. A direction vector was associated with each monosaccharide, which defined a "head" and a "tail". The head and tail represent points of attachment for covalent bonds and, where appropriate, can correspond to reducing and non-reducing ends of oligosaccharides and polysaccharides. Additional "left" and "right" covalent bonding sites were defined by a diameter perpendicular to the direction vector. To allow distinction between different molecules, glucoses were coloured light blue, xyloses magenta, arabinoses yellow, glucuronic acids brown, ferulic acids red, galacturonic acids green and enzymes white. More information on these classes is given in the Supplementary Information.

\subsection{Assembling the Simulation Environment}

A user-specified number of CMFs is inserted into the simulation environment to create a scaffold to which the first hemicellulose network of the PCW is attached. The first step in constructing this network is the insertion of $(1,3 ; 1,4)$ - $\beta$-glucans, with each attaching a CMF at a (linear) run of adjacent $(1,4)$-linked $\beta$-glucosyl residues. The network is completed by the attachment of xyloglucans and GAXs to CMFs, in one of two configurations: tethered (attached to two different CMFs) or semi-tethered (one end of the polymer backbone attached to a CMF and the other end floating). Attachment to CMFs occurs via the end three monosaccharides of the backbone for both GAX and xyloglucan. The second network is formed by inserting floating hemicelluloses and pectins in the spaces within the first network. During the formation of both the networks, if two ferulates (each from a different GAX) are proximal and in the correct configuration, these may covalently bond to create a cross-linking diferulate.

During the construction of the PCW, an algorithm ensures the polysaccharides are placed so that the bond angles between all covalently bonded monosaccharides are maintained within a specified tolerance. This algorithm also ensures that monosaccharides are not placed so that they spatially 
overlap. These constraints place considerable restrictions on the placements of polysaccharides, and the process of building the PCW is computationally intense.

\subsection{Simulating Enzymatic Action}

One enzyme class was written to represent all types of enzymes, in order that all enzymes could be stored in the same C++ STL container. Properties of the class include the types of catalytic activity an enzyme object possesses, and the dimension and shape of the enzyme. Catalytic activity is specified when each individual enzyme is created, in terms of the types of covalent bonds and degree of polymerisation (DP) of oligosaccharides that can be cleaved, and the cleavage time. Similarly, enzyme shape and dimension is specified when each enzyme is created. Additional algorithms can be contained which are specific to each enzyme being simulated. While we have represented each monosaccharide and enzyme as a sphere, in reality enzymes exhibit far more complex shapes, and including a method to specify enzyme shape makes provision to include a range of enzyme shapes in future developments of the model. The progress of time occurs implicitly with an iterative sequence (Figure 1) in which enzymatic action is simulated, although in the current version of the model iterations have not been calibrated to a unit of time. More information is supplied in the Supplementary Information.

In each iteration diffusion of enzymes is modelled by a step of random size and direction, collisions are detected and resolved, and the proximity of an enzyme to bonds it can cleave is detected. An algorithm then determines whether or not a bond will be cleaved and the time (in iterative steps) taken to cleave the bond (during which the enzyme is bound to the site and remains stationary). Cleavage is simulated by changing Boolean flags for covalent bonds from true to false. Following this, the algorithm detects monosaccharides or oligosaccharides that have been cleaved from the PCW structure, and which are below a threshold chain length. These are identified as breakdown products, and the last step of the iteration is recording and removing them from the simulation (with a low probability inversely proportional to their DP to account for time taken for diffusion, and allowing a window of opportunity for further degradation of the product).

Collision detection is required to simulate steric effects on the diffusion of enzymes and their access to bonds, and also to detect when an enzyme has encountered (collided with) a bond that it can cleave. There are a number of efficient methods for dealing with collision detection [57] and, of these, we used the so called Octagonal Tree approach which is discussed in detail by Lucchesis [58]. Our implementation of an OctTree class was a modified version of a $\mathrm{C}++$ class available online [59]. The collision detection algorithm determines if two molecules have collided by comparing the separation of their centres with the sum of their bounding radii. For this to work effectively, and to prevent enzymes stepping through molecules, the maximum step size was limited to half the radius of the smallest molecule in the simulation (i.e., 0.5 glucose radii). 
Figure 1. Structure diagram indicating the algorithm for simulating the enzymatic degradation of grass primary cell walls. A curved arrow through lines indicates continuous repetition; diamond shaped boxes indicate decision points.

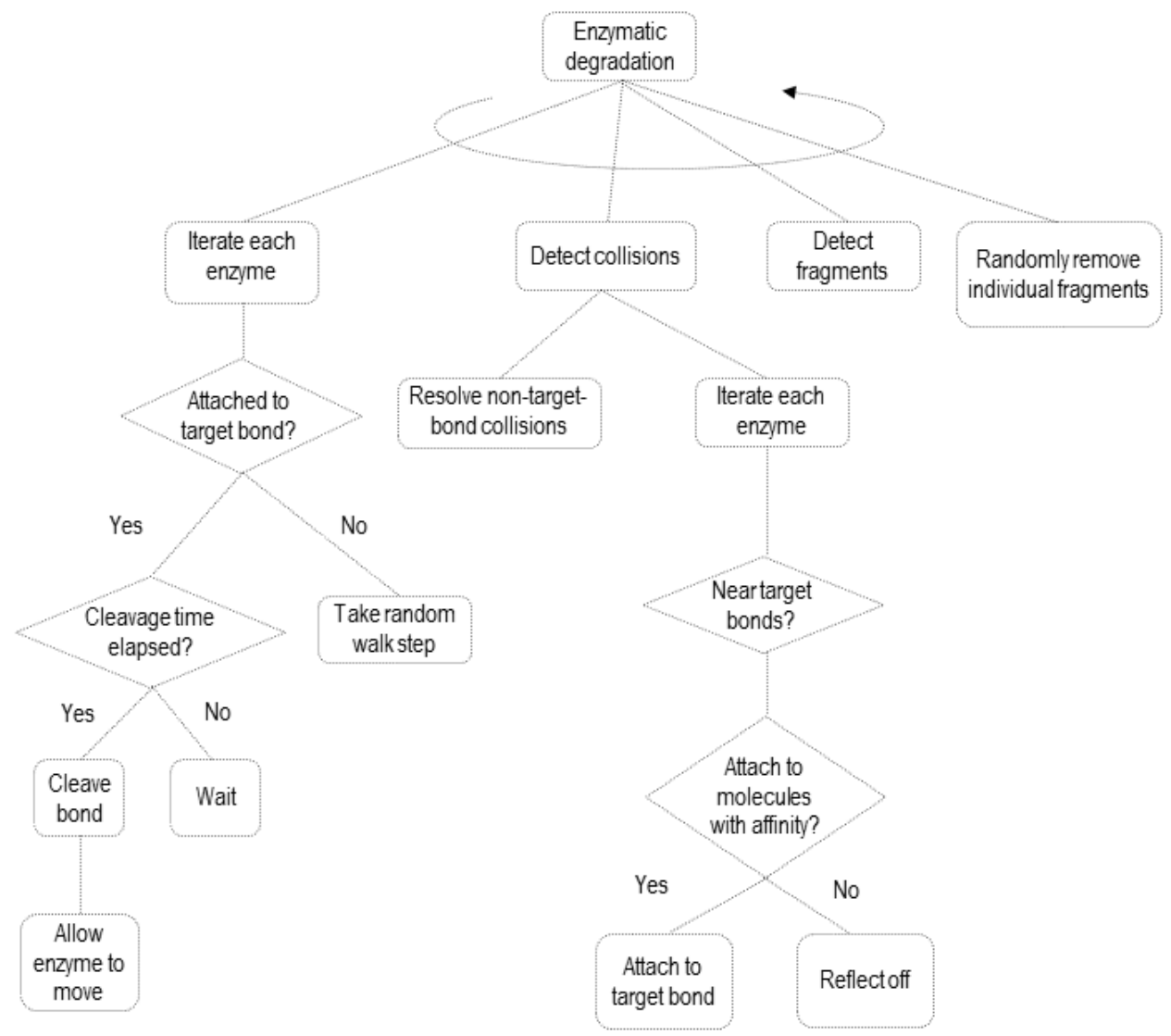

\section{Results and Discussion}

\subsection{Construction of the Grass Primary Cell Wall}

As a proof of principle we modelled enzyme degradation of a mesophyll cell wall (MCW) from the leaf of perennial ryegrass (Lolium perenne cv. Perma) [20,60-62]. Our simulation was of a small volume of cell wall, involving segments of nine CMFs arranged in parallel (with the cellulose molecules 60 glucosyl residues long). We included 245 GAXs, 93 xyloglucans, 100 pectins, and $35(1,3 ; 1,4)$ - $\beta$-glucans.

CMFs were modelled as bundles of 28 cellulose molecules ( $43 \%$ crystal interior), based on findings by Smith et al. [63] who performed $\mathrm{C}^{13}$-NMR spectroscopy on Italian ryegrass. Recent combined $\mathrm{X}$-ray scattering and NMR spectroscopy data from mung bean (Vigna radiata) primary walls [64] supports an 18 cellulose molecule microfibril, and this could be implemented in our model as an alternative. In addition, experiments have found kinks in CMFs [65] and atomic modelling studies have suggested that CMFs are twisted [66,67]. Whether or not such findings are real or artifacts of experimental procedure and/or modelling assumptions has been questioned [65,68]. We have not included twists or kinks in CMFs in our model but these can be introduced at a later date. All $35(1,3 ; 1,4)$ - $\beta$-glucans were specified to be attached to CMFs, as shown in Figure 2. 
Figure 2. The first stage of constructing the simulated wall of a perennial ryegrass mesophyll cell involved the attachment of $(1,3 ; 1,4)-\beta$-glucans to CMFs. Each blue sphere represents a glucose molecule.

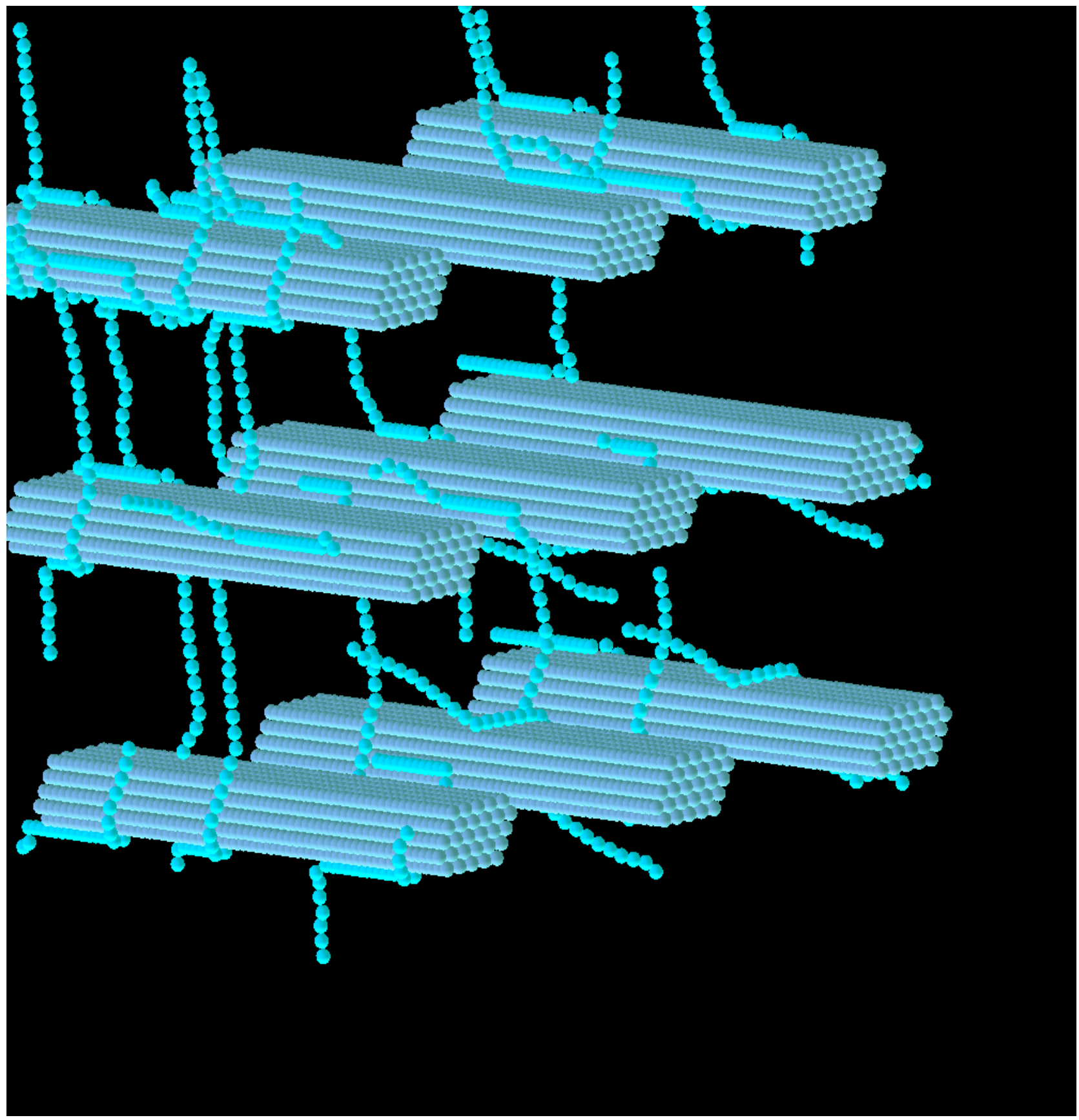

We assumed that 33\% of xyloglucans and 7\% of GAXs are tethered (attached to two different CMFs), and that $67 \%$ of xyloglucans and $13 \%$ of GAXs are semi-tethered (attached to one CMF). The progress of the simulated PCW is shown in Figure 3 with some of the tethered and semi-tethered hemicelluloses inserted during construction of the first hemicellulose network. 
Figure 3. The second stage involved attachment of tethered and semi-tethered xyloglucans and glucuronoarabinoxylans (GAXs) to form the first hemicellulose network (shown partially complete). Glucose, xylose, arabinose, glucuronic acid and ferulic acid are represented by blue, magenta, yellow, brown and red spheres respectively.

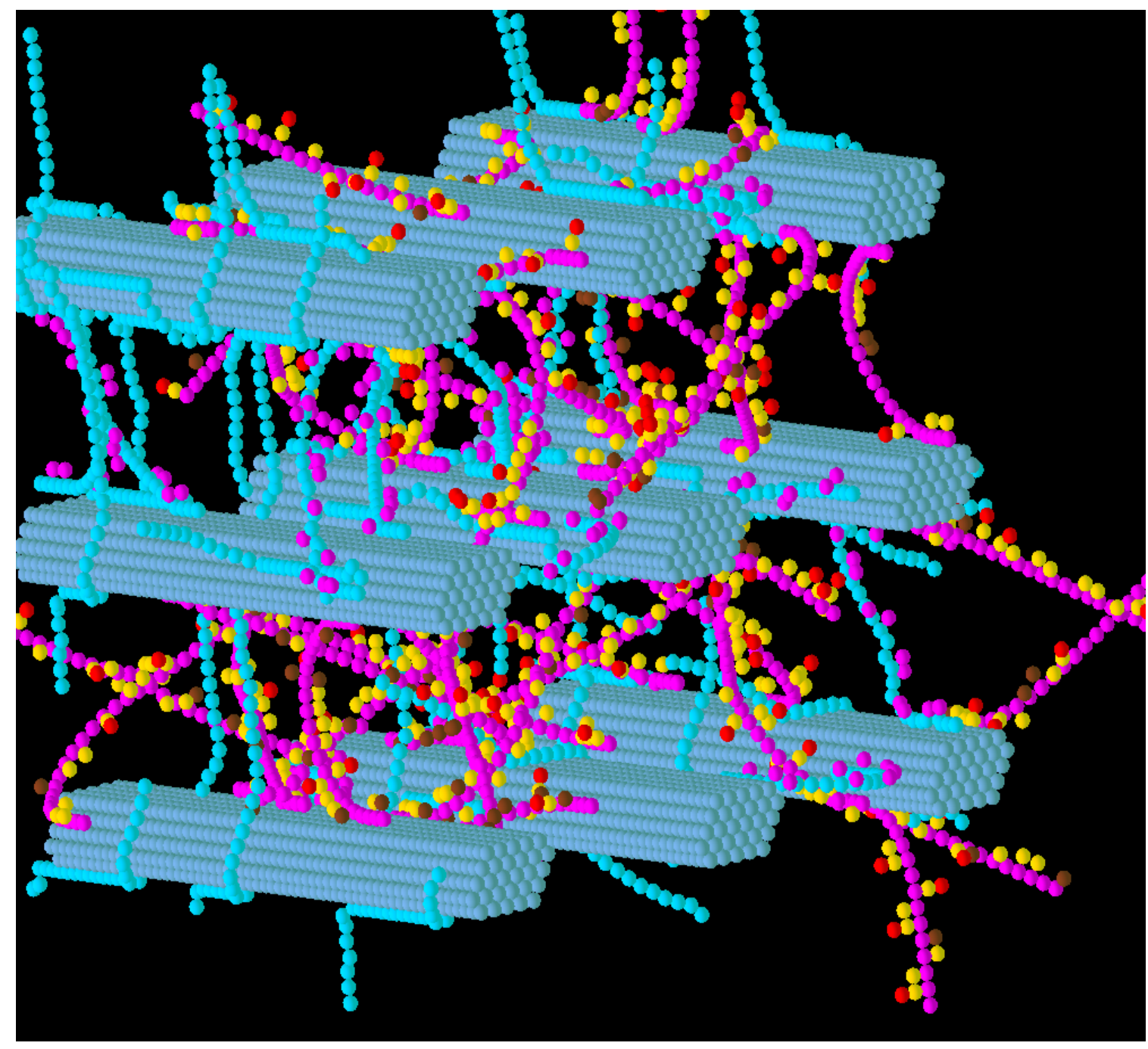

After completion of the first polymer network, pectins and the remaining $80 \%$ of GAXs were inserted as floating polymers to form the second polymer network (Figure 4). The nine CMFs contain 15,120 glucosyl residues between them, and contribute $46.6 \%$ of the monosaccharides in the simulated wall. The 245 GAXs, 3 xyloglucans, 100 pectins and $35(1,3 ; 1,4)$ - $\beta$-glucans in the simulation contain respectively 9670, 4028, 2568 and 1028 monosaccharides, contributing $29.8 \%, 12.4 \%, 7.9 \%$ and $3.2 \%$ of the simulated wall. This is in good agreement with the analysis by Chesson and colleagues [20,60-62] who found the composition of the perennial ryegrass MCW to be $46.6 \%$ cellulose, $29.8 \%$ GAX, $12.5 \%$ xyloglucans, $7.8 \%$ pectins and $3.2 \%(1,3 ; 1,4)-\beta$-glucans. Of the 1434 ferulates in the simulation, only $18(1.2 \%)$ formed covalent bonds with another ferulate, and thus only nine diferulate cross-bridges were formed between the 245 GAXs. 
Figure 4. Free-floating GAXs and pectins (homogalacturonans) were inserted into the first hemicellulose networks to complete the model. Glucose, xylose, arabinose, glucuronic acid, ferulic acid and galacturonic acid are represented by spheres coloured blue, magenta, yellow, brown, red and green respectively.

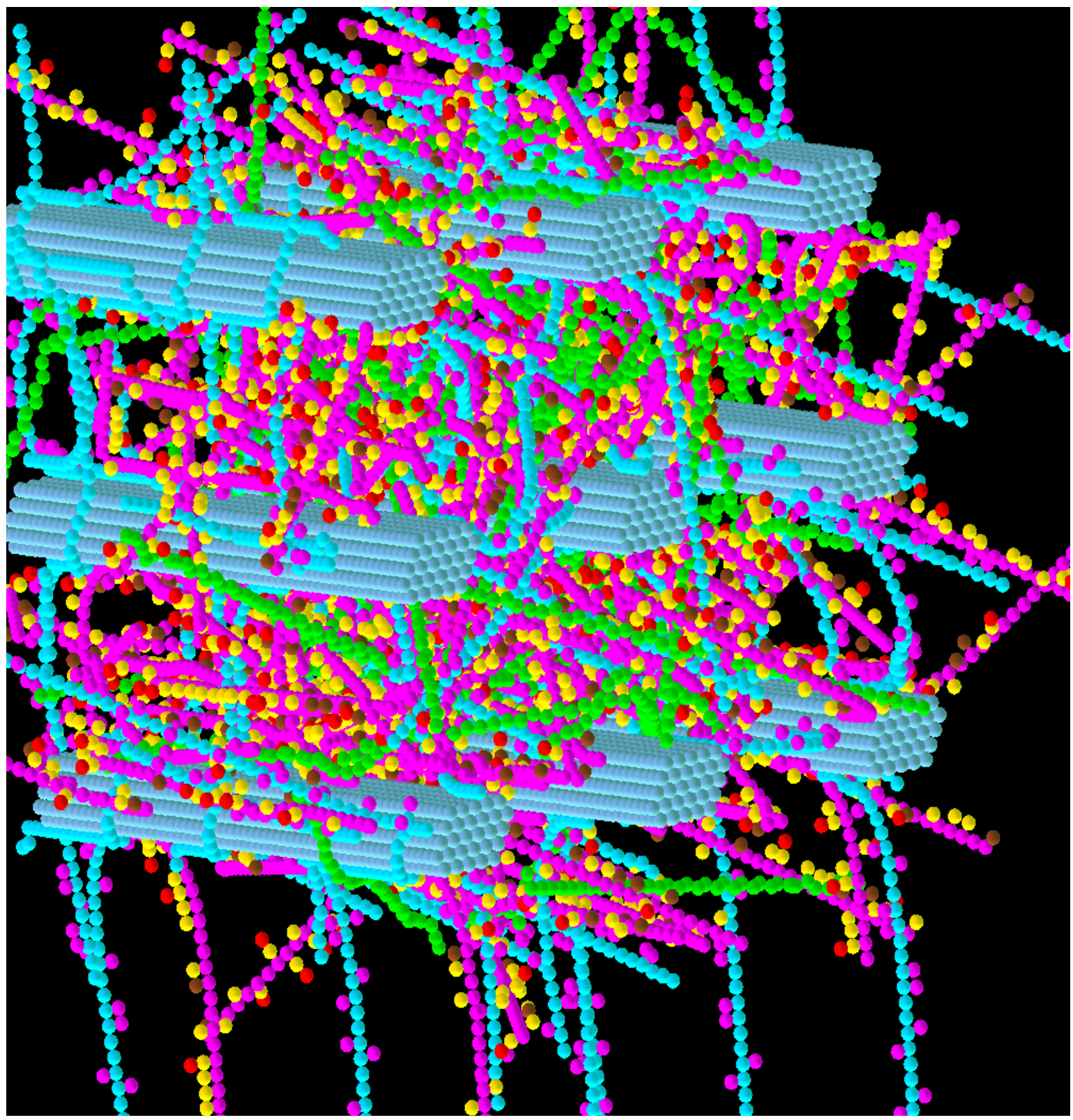

In the current version of our model, all monosaccharides, including uronic acids, comprising the different polysaccharides were assumed to be the size of a glucose molecule. However differing sized monosaccharides are readily implemented by adjusting parameters. Further, we did not follow the convention in carbohydrate chemistry of depicting poly- or oligosaccharides with non-reducing ends oriented to the left and reducing ends to the right; such a convention is inconsequential since the viewing angle can be rotated in the model and the polysaccharides (some of which are highly curved) point in a variety of directions. 


\subsection{Simulation of Enzymatic Action}

We chose to model three enzymes produced by Fibrobacter succinogenes S85 because this organism (i) does not secrete cellulosomes (which would be more complex to model than individual enzymes) and (ii) degrades but cannot utilise arabinoxylan. The first two enzymes were Cel51A and Ce19D, which have been characterised and shown to act synergistically [69,70]. Cel51A is an endoglucanase that acts on cellulose, but also $(1,3 ; 1,4)-\beta$-glucans and xyloglucans mainly producing oligosaccharides with a DP of 2-5. Cel 9D is an exoglucanase that processively removes unsubstituted glucosyl residues from the non-reducing end of oligosaccharides with DPs $>2$, including cellooligosaccharides, xyloglucan oligosaccharides and $(1,3 ; 1,4)-\beta$-glucan oligosaccharides.

The third enzyme is endoxylanase 1 described by Matte and Forsberg [71], which additionally has $\alpha$-arabinofuranosidase activity. It was chosen to investigate possible synergies with Cel51A and Ce19D. Further information on these enzymes and how they were modelled is given in the supplementary information. Three enzyme combinations were modelled, each of which contained the same number of enzymes capable of breaking $(1,4)-\beta$-glucosidic bonds: (i) 40 Cel51A enzymes; (ii) 20 each of Cel51A and Ce19D; and (iii) 20 each of Cel51A, Ce19D and endoxylanase 1, each attacking the cell wall depicted in Figure 4. Simulations were started with the enzymes placed in the 'biofilm" below the section of cell wall. Enzymes moved randomly with collision detection, and were thus constrained by the presence of other molecules. Enzymes which reached the bounding box of the simulation environment were not reflected back, but rather deemed to have irreversibly penetrated deeper into the cell wall structure, and were removed and replaced in the biofilm area.

For each enzyme combination, five simulations (each 50 million iterations long) were run on a single thread of an Intel Core2 Duo $2.40 \mathrm{GHz}$ processor. Graphics rendering was extremely resource-hungry with a tendency to slow the simulation. Thus simulations were run with graphics turned off, and had a mean run-time of $23.6 \pm 0.3 \mathrm{~h}$. Figure 5 contrasts the end results of a simulation run involving just Cel51A with a simulation run involving all three enzyme types (Figure 6). Activity on cellulose lagged that on hemicelluloses in all cases, which is consistent with these hemicelluloses providing protection to CMFs.

The model results showed synergies between Cel51A and Ce19D with the combined 20 Cel51A and 20 Ce19D enzymes having 102\%, 67\% and 37\% more activity on molecules and oligosaccharides of cellulose, $(1,3 ; 1,4)-\beta$-glucan and xyloglucan respectively, when compared with the activity of 40 Cel51A enzymes (Figure 7). An additional 20 endoxylanase 1 enzymes further increased activity on cellulose, $(1,3 ; 1,4)-\beta$-glucan and xyloglucan by respectively $40 \%$ and $6 \%$ and $11 \%$, when compared with the combination of $20 \mathrm{Cel} 51 \mathrm{~A}$ and $20 \mathrm{Cel} 9 \mathrm{D}$ (Figure 7). 
Figure 5. The degraded perennial ryegrass mesophyll cell wall (MCW) after the simulated enzyme action showing degradation of hemicelluloses and cellulose at the periphery of the wall after a simulation run involving Cel51A enzymes alone. Glucose, xylose, arabinose, glucuronic acid, ferulic acid and galacturonic acid are represented by the smaller spheres coloured blue, magenta, yellow, brown, red and green respectively. Larger purple spheres represent Cel51A enzymes.

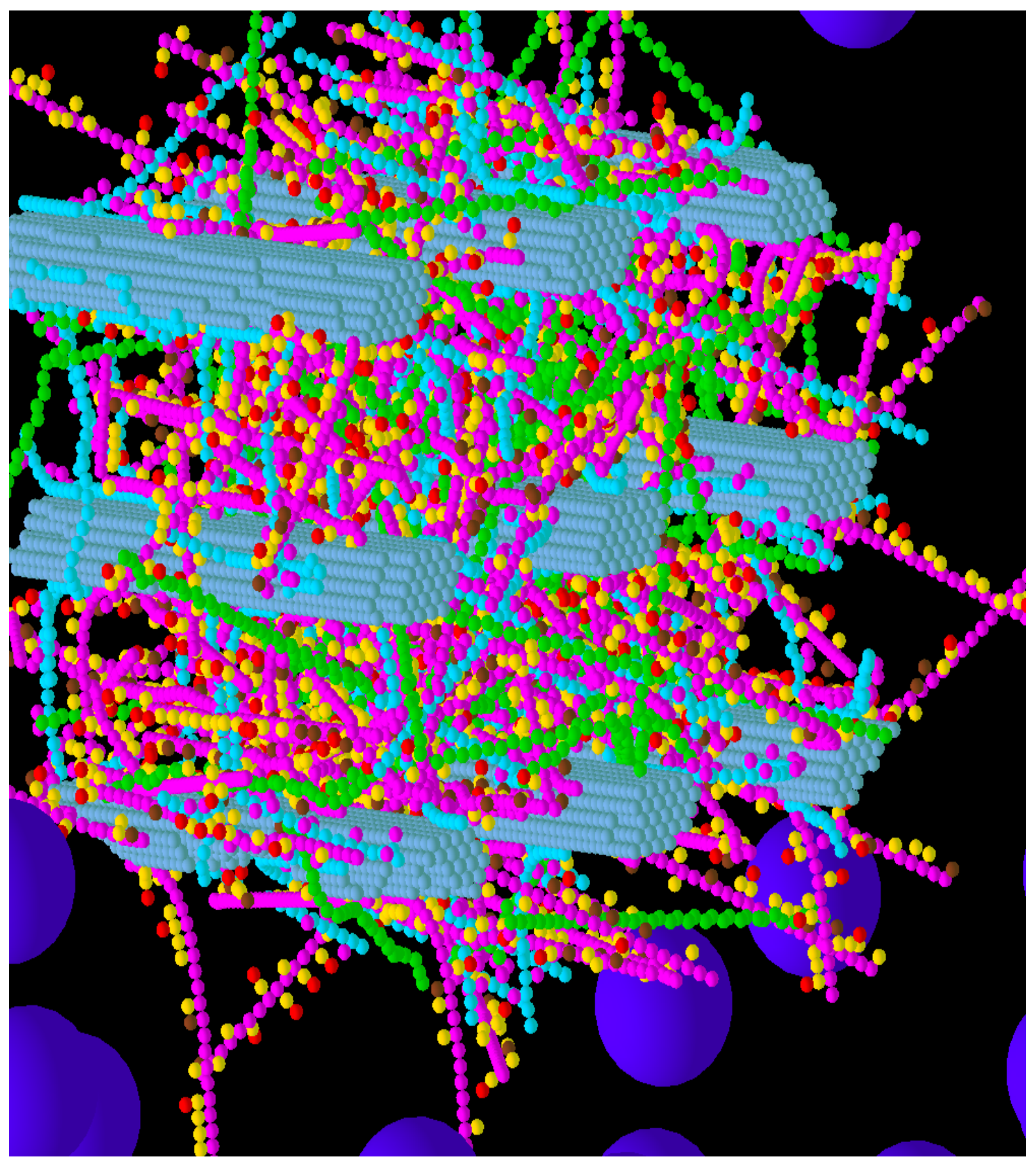


Figure 6. The degraded perennial ryegrass $\mathrm{MCW}$ after the simulated enzyme action showing degradation of hemicelluloses and cellulose at the periphery of the wall after a simulation run involving a combination of Cel51A, Ce19D and endoxylanase 1. Glucose, xylose, arabinose, glucuronic acid, ferulic acid and galacturonic acid are represented by the smaller spheres coloured blue, magenta, yellow, brown, red and green respectively. Larger spheres coloured purple, blue and magenta represent Cel51A, Cel9D and endoxylanase 1 , respectively.

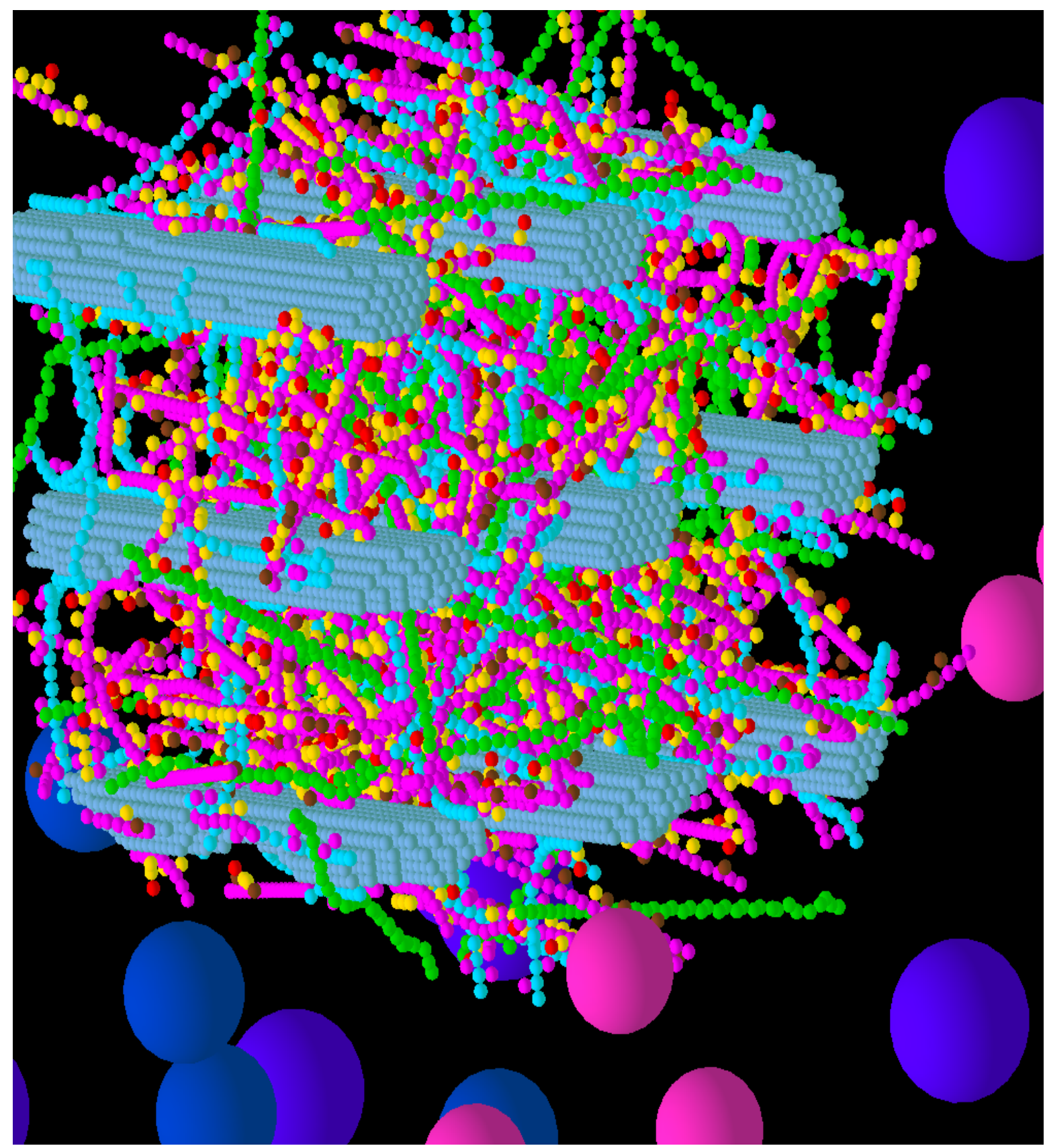


Figure 7. Simulation results for cumulative enzyme activities on glucosidic bonds versus simulation progress (in iterations), for three enzyme combinations (with constant number of catalytic domains targeting glucosidic bonds). Synergies were evident between Ce151A and Ce19D, and Cel51A, Cel9D and endoxylanase 1. Combination 1: 40 Cel51A (endoglucanase) enzymes; Combination 2: 20 Cel51A (endoglucanase) and 20 Ce19D (exoglucanase) enzymes; Combination 3: 20 Cel51A (endoglucanase) and 20 Cel9D (exoglucanase) and 20 endoxylanase 1 (endoxylanase with $\alpha$-arabinofuranosidase activity) enzymes.

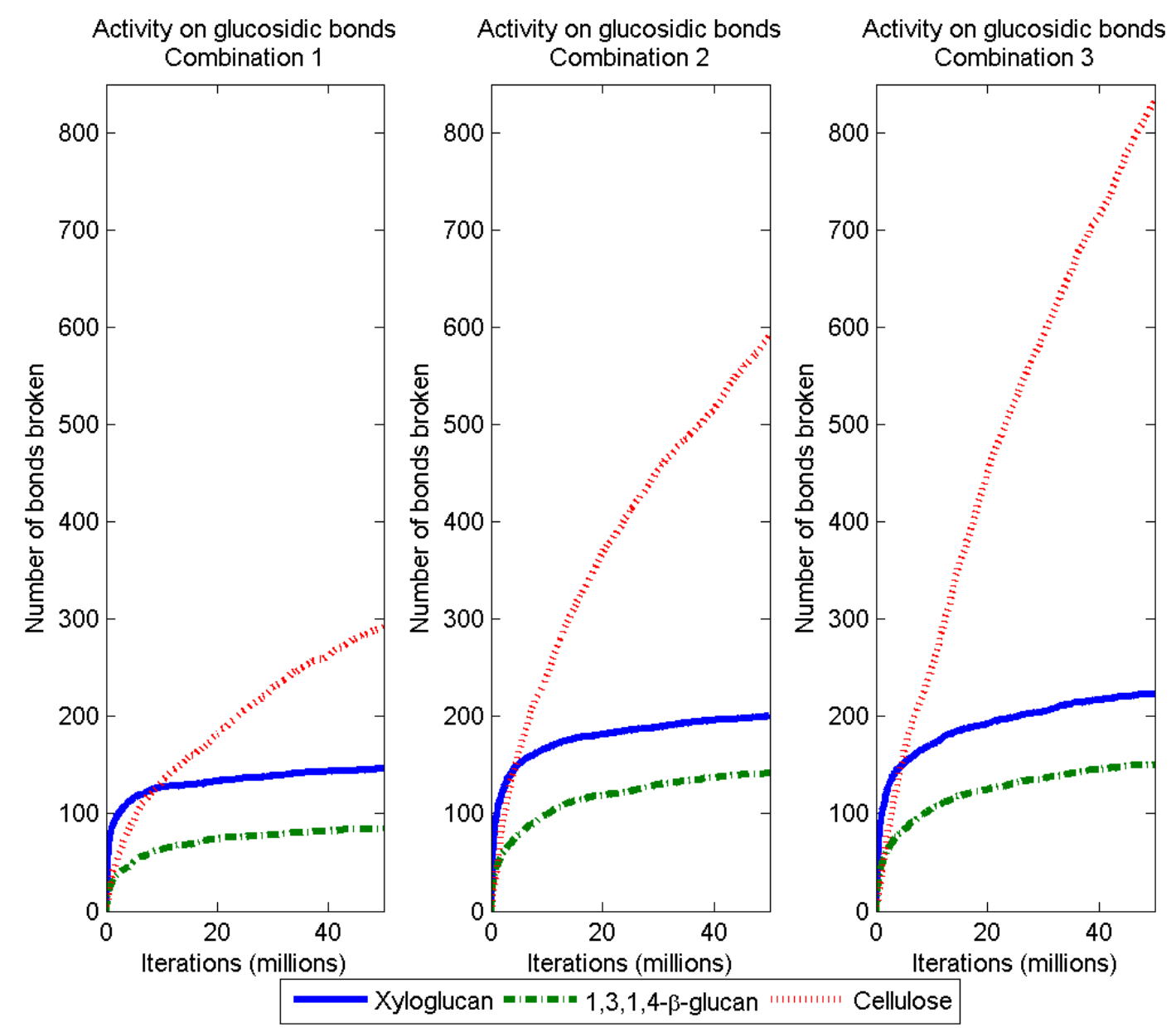

Considering activity per 20 Cel51A enzymes, Figure 8 shows that Cel9D enhanced the per-enzyme-activity of Cel51A on xyloglucan by $87 \%$, compared with $53 \%$ for activity on $(1,3 ; 1,4)-\beta$ glucan and $44 \%$ for cellulose. The combination of endoxylanase 1 and Ce19D increased the per-enzyme-activity of Cel51 on xyloglucan, $(1,3 ; 1,4)-\beta$-glucan and cellulose by respectively $111 \%$, $61 \%$ and $123 \%$ respectively, when compared with Cel51 alone (Figure 8).

Endoxylanase 1 had a synergistic effect on the activity of Ce19D activity on cellulose (33\%) and xyloglucan (8\%) and $(1,3 ; 1,4)$ - $\beta$-glucan (7\%) (Figure 9). Endoxylanase 1 activity on the arabinosidic bonds of GAX was significantly greater than on xylosidic bonds and arabinoses (including arabinoses esterified to ferulic acid) were produced as by-products in greater number and earlier than xylooligosaccharides (Figure 10), which is consistent with the branches providing protection to the backbone. 
Figure 8. Simulation results showing the activity per $20 \mathrm{Cel} 51 \mathrm{~A}$ enzymes on glucosidic bonds versus simulation progress (in iterations), for three enzyme combinations. Synergies existed both between Cel51A and Ce19D, and between Cel51A, Ce19D and endoxylanase 1. Combination 1: 40 Cel51A (endoglucanase) enzymes; Combination 2: 20 Cel51A (endoglucanase) and 20 Cel9D (exoglucanase) enzymes; Combination 3: 20 Cel51A (endoglucanase), 20 Cel9D (exoglucanase) and 20 endoxylanase 1 (endoxylanase with $\alpha$-arabinofuranosidase activity) enzymes.

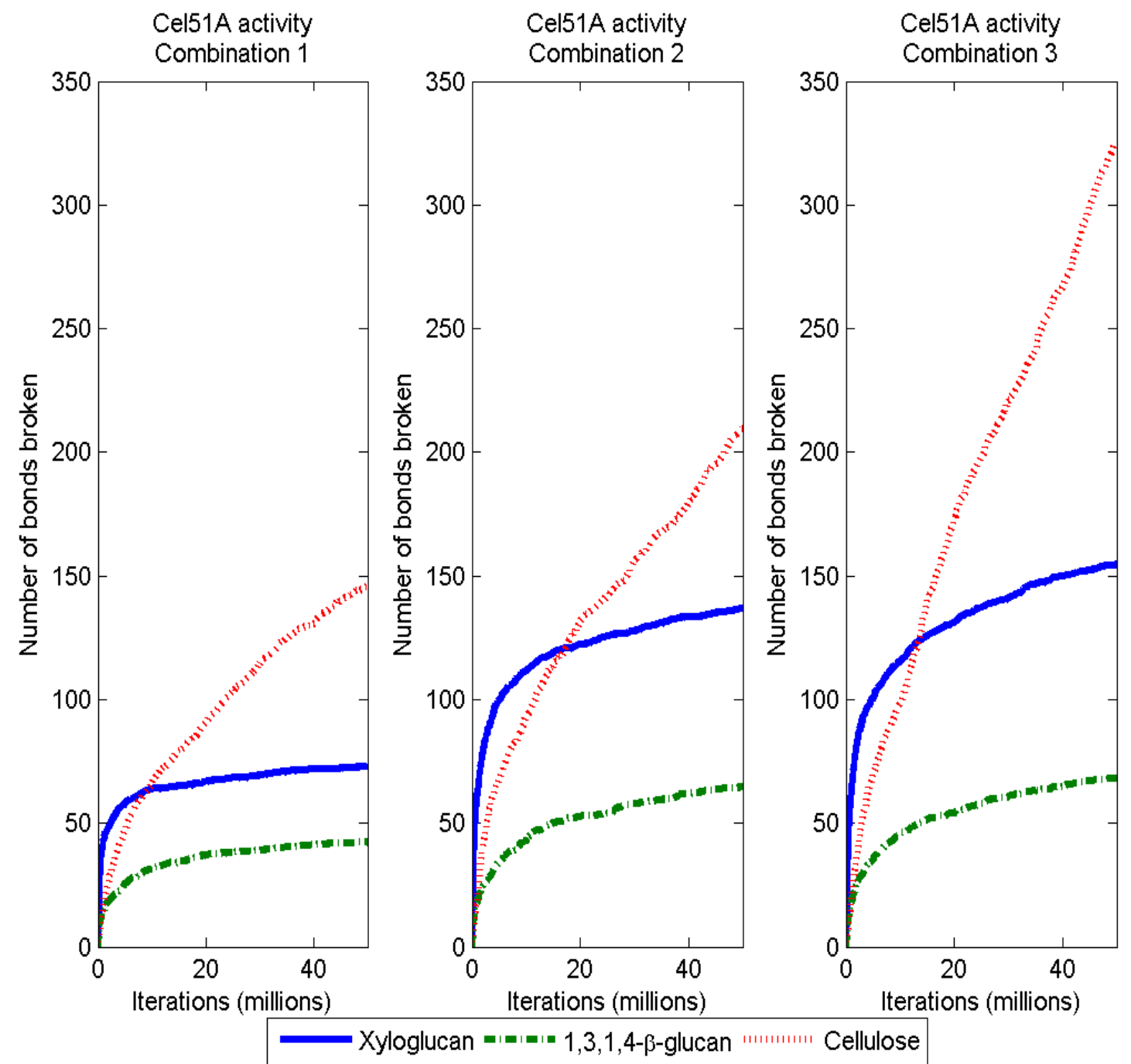

The model predicted a numerous variety of breakdown products, varying in the lengths of the oligosaccharide backbones and in the combinations of side branches. The simulation keeps track of the polysaccharide that a breakdown product originates from. Breakdown products from $\beta$-glucans (cellulose, 1,3;1,4- $\beta$-glucan, and xyloglucan) are summarised in Table 1, although for clarity, information on branching structure and the presence of 1,3-linkages in oligosaccharides from respectively xyloglucan and $(1,3 ; 1,4)$ - $\beta$-glucan have been suppressed. Variability between runs for the same enzyme combination are represented as standard deviations. Unsurprisingly, Cel51A, being an endoglucanase, did not produce glucose. Interestingly, while glucosyl trimers were the most prominent product of Cel51A when acting on cellulose or $(1,3 ; 1,4)$ - $\beta$-glucan, glucosyl tetramers were the most prominent from xyloglucan. The effect of introducing Ce19D with Cel51A, in addition to increasing 
the degradation of the cell wall by producing $11 \%$ more glucosyl residues (either as glucose or oligosaccharides), was to shift the size distribution of oligosaccharides towards glucose, with a reduction in larger oligosaccharides. Endoxylanase 1 increased production of glucosyl residues by $33 \%$, but appeared to have little effect on the degradation of $(1,3 ; 1,4)-\beta$-glucan or xyloglucan. Rather, endoxylanase 1 appeared to accelerate the degradation of cellulose, and significantly increased the production (from cellulose) of oligosaccharides with DPs 1-5 when compared with Cel51A and Ce19D in combination, and of oligosaccharides of DP 6 when compared with Cel51A alone.

Figure 9. Simulation results showing the activity of Ce19D enzymes on glucosidic bonds versus simulation progress (in iterations), for two different enzyme combinations. Endoxylanase 1 and Ce19D had significant synergies for degrading cellulose. Combination 2: 20 Cel51A (endoglucanase) and 20 Cel9D (exoglucanase) enzymes; Combination 3: 20 Cel51A (endoglucanase), 20 Cel9D (exoglucanase) and 20 endoxylanase 1 (endoxylanase with $\alpha$-arabinofuranosidase activity) enzymes.

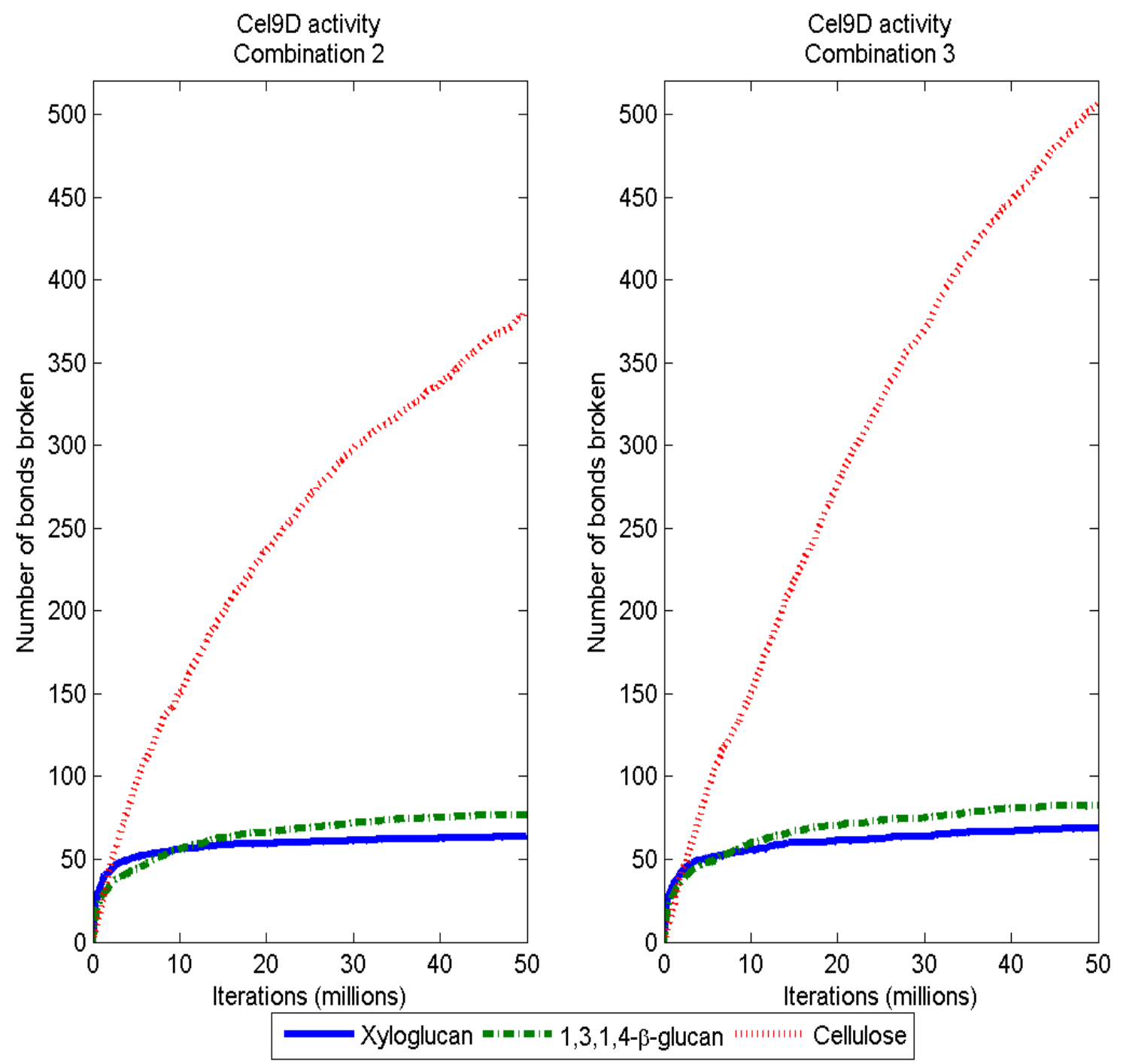


Figure 10. Simulation results showing the activity of endoxylanase 1 on arabinoxylan for the enzyme combination with equal numbers of Cel51A (endoglucanase), Cel9D and endoxylanase 1 (an endoxylanase that also has $\alpha$-arabinofuranosidase activity). Arabinoses counted as breakdown products include some esterified to ferulic acid, and xylooligosaccharides include those with branches.
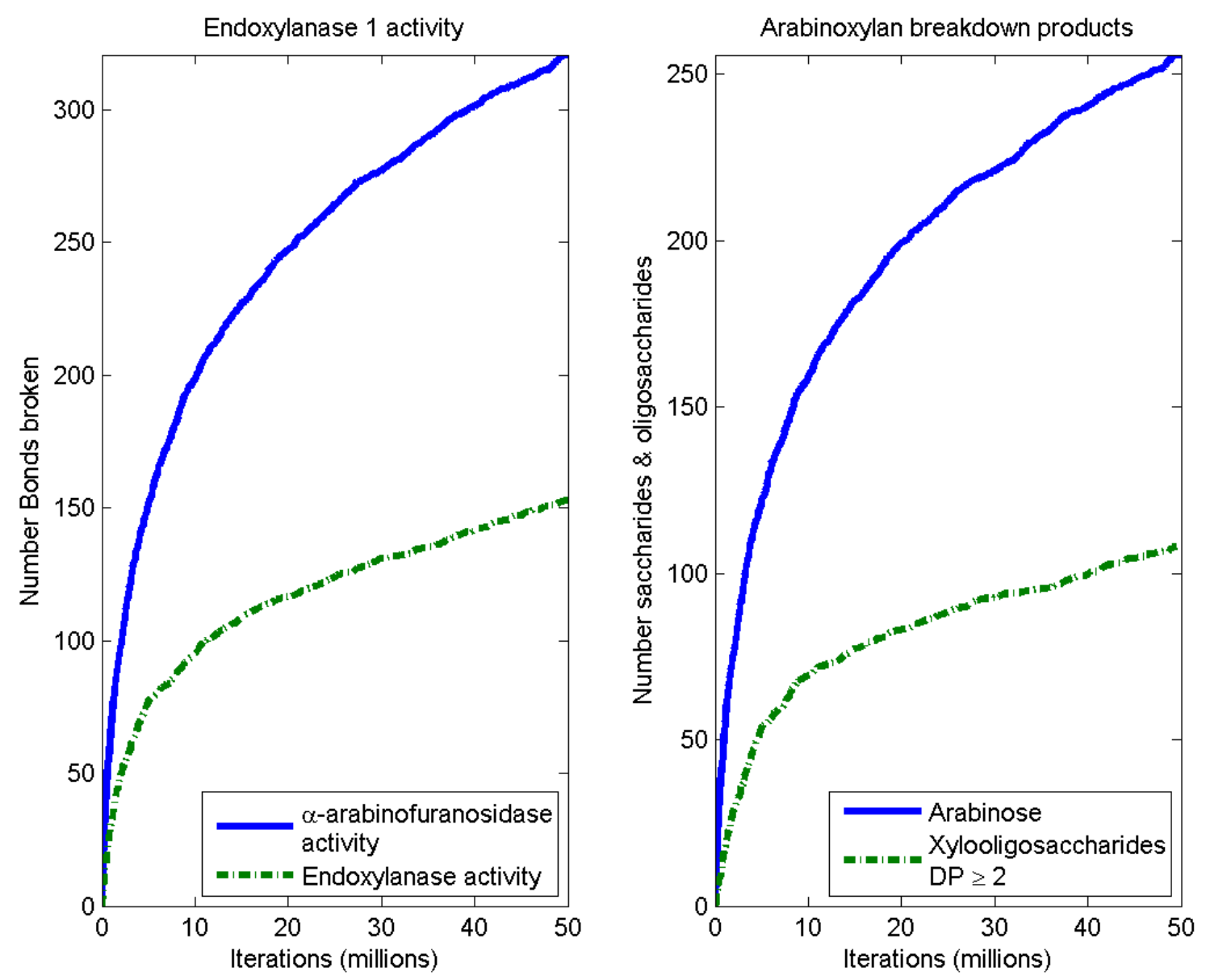

\subsection{Considerations}

We have achieved a model that uses rules on architecture to construct a 3-D representation of the structure of a mesophyll cell wall (MCW) from a perennial ryegrass leaf, and then predicts its enzymatic degradation by simulating the diffusion (with steric hindrance) and synergistic action of catalytic enzymes using an agent-based approach. Our simulations involving three characterised enzymes from $F$. succinogenes S85 showed synergies between the endoglucanase Cel51A and the exocellulase Ce19D, in terms of increased activity on glucosidic bonds. Qi et al. [69] found Cel51A and Cel9D showed in vitro synergies when degrading crystalline cellulose, compared with Cel51A alone. Our simulation result cannot be compared quantitatively with this result since the substrate being degraded differed. However on a qualitative level our simulation agrees with the experiment, highlighting the potential of our approach for investigating enzyme synergies.

Our simulations also showed that endoxylanase 1 had a synergistic effect on the activities of Cel51A and Ce19D, allowing faster degradation of cellulose, very likely through increasing access to cellulose by removing arabinoxylans. The pattern of degradation suggests that during the course of the 
simulations, hemicelluloses surrounding the outer CMFs reduced access to these CMFs until they were degraded. This is consistent with hemicelluloses protecting CMFs from enzymatic degradation in vivo, and highlights the potential for synergies between enzymes with differing activities.

Table 1. Glucosyl-containing oligosaccharide breakdown products predicted by simulations of degradation of the mesophyll primary plant cell wall by three different enzyme combinations. Values are means and standard deviation (in parentheses) for the number of glucoses and glucosyl-containing oligosaccharides from the five simulation runs for each enzyme combination. The number of branches on xyloglucan oligosaccharides and the number of 1,3-linkages in $(1,3 ; 1,4)$ - $\beta$-glucan oligosaccharides has been omitted, although detailed in simulation output. DP: degree of polymerisation; Combination 1:40 Cel51A (endoglucanase) enzymes; Combination 2:20 Cel51A (endoglucanase) and 20 Ce19D (exoglucanase) enzymes; Combination 3:20 Cel51A (endoglucanase), 20 Ce19D (exoglucanase) and 20 endoxylanase 1 (endoxylanase with $\alpha$-arabinofuranosidase activity) enzymes. The same superscripted letter appearing to the right of any two entries in a row indicates that the values are significantly different at the $5 \%$ level.

\begin{tabular}{|c|c|c|c|c|c|c|c|}
\hline \multirow[t]{2}{*}{ Source polysaccharide } & \multirow{2}{*}{$\frac{\text { DP }}{1}$} & \multicolumn{2}{|c|}{ Combination 1} & \multicolumn{2}{|c|}{ Combination 2} & \multicolumn{2}{|c|}{ Combination 3} \\
\hline & & 0.0 & $(0)^{a, c}$ & 76.8 & $(6.5)^{\mathrm{a}}$ & 82.2 & $(9.5)^{\mathrm{c}}$ \\
\hline \multirow{5}{*}{$(1,3 ; 1,4)$ - $\beta$-Glucan } & 2 & 10.3 & (6) & 7.6 & (4) & 9.7 & $(4.6)$ \\
\hline & 3 & 14.6 & $(3)^{a, c}$ & 9.6 & $(2.2)^{\mathrm{a}}$ & 9.4 & $(2.7)^{\mathrm{c}}$ \\
\hline & 4 & 7.1 & $(2.7)$ & 5.7 & $(1.7)$ & 5.5 & $(2.7)$ \\
\hline & 5 & 5.3 & $(2.1)$ & 3.5 & (2.6) & 3.5 & (2.5) \\
\hline & 6 & 4.4 & $(2.7)$ & 4.9 & $(3.5)$ & 4.6 & $(3.5)$ \\
\hline \multirow{6}{*}{ Cellulose } & 1 & 0.0 & $(0)^{a, c}$ & 381.4 & $(43.2)^{\mathrm{a}, \mathrm{b}}$ & 506.0 & $(43.1)^{b, c}$ \\
\hline & 2 & 83.8 & $(11.7)^{\mathrm{c}}$ & 68.0 & $(14)^{b}$ & 118.0 & $(23.3)^{b, c}$ \\
\hline & 3 & 98.2 & $(8.7)^{\mathrm{a}}$ & 53.8 & $(17.2)^{a, b}$ & 81.6 & $(14.7)^{b}$ \\
\hline & 4 & 37.4 & $(8.7)^{\mathrm{a}}$ & 25.2 & $(5.1)^{a, b}$ & 40.8 & $(10.2)^{b}$ \\
\hline & 5 & 23.0 & $(2.8)^{\mathrm{a}}$ & 14.8 & $(3.4)^{a, b}$ & 27.4 & $(10.5)^{b}$ \\
\hline & 6 & 13.6 & $(4.3)^{\mathrm{c}}$ & 17.0 & $(6.6)$ & 27.4 & $(8.8)^{\mathrm{c}}$ \\
\hline \multirow{6}{*}{ Xyloglucan } & 1 & 0.0 & $(0)^{\mathrm{a}, \mathrm{c}}$ & 64.0 & $(5.9)^{\mathrm{a}}$ & 68.8 & $(8.1)^{c}$ \\
\hline & 2 & 11.5 & $(4.7)$ & 8.6 & $(4.2)$ & 11.9 & $(4.2)$ \\
\hline & 3 & 27.2 & $(1.5)^{\mathrm{a}, \mathrm{c}}$ & 48.6 & $(6.8)^{\mathrm{a}}$ & 54.2 & $(6.9)^{c}$ \\
\hline & 4 & 46.6 & $(5.8)^{\mathrm{a}, \mathrm{c}}$ & 32.8 & $(4.4)^{\mathrm{a}}$ & 35.6 & $(6.4)^{c}$ \\
\hline & 5 & 24.2 & $(3.7)^{\mathrm{a}}$ & 17.6 & $(2.1)^{\mathrm{a}}$ & 20.4 & $(2.1)$ \\
\hline & 6 & 4.8 & $(3.5)$ & 3.2 & $(2.2)$ & 3.8 & $(1.6)$ \\
\hline \multicolumn{2}{|c|}{ Glucosyl residues removed } & 1592 & (51) & 1764 & (196) & 2350 & $(228)$ \\
\hline
\end{tabular}

The trends in the simulation suggested that $F$. succinogenes could release glucose faster with endoxylanase 1 than without, and this may explain the reason that organism secretes endoxylanases even though it cannot utilise arabinoxylan breakdown products. The trade-offs between cost of producing an endoxylanase and the extra glucosyl residues released before it is defunct would determine the benefit of this strategy, and this is a question that could potentially be investigated with our model.

The ability of our model to simulate how enzyme combinations influence the profiles of monosaccharides and oligosaccharides in the array of breakdown products is a significant capability 
since these breakdown products can influence the end products of fermentation. Further, breakdown products may govern the growth rates of competing microbial species, and thus contribute to factors that determine the composition of the microbiota. For example, F. succinogenes appears to readily utilise glucose and cellobiose [72], whereas some microorganisms utilise larger oligosaccharides more effectively [73]. Certainly a study of Butyrivibrio proteoclasticus $\mathrm{B} 316^{\mathrm{T}}$ enzymes suggests a variety of complex oligosaccharides resulting from extracellular hydrolysis are metabolized within the cell [74]. Thus the model outputs could be used as inputs into models of microbial growth to make predictions of the competitiveness of different microbial species for different compositions of the PCW. Furthermore, the effect of introducing novel enzymes into a mix of enzymes already present could be ascertained for potential improvements in the nutrition of the ruminant.

\subsection{Refinement of the Model}

The model assumed that proximity of an enzyme to a target glycosidic bond was the only requirement for cleavage. This implicitly assumes that the binding domain of an enzyme would position the catalytic domain in the correct orientation relative to the bond to be cleaved. A more refined representation of enzyme shape, including the positions of catalytic and binding domains, would allow for a more detailed consideration of enzymatic activity, and could potentially alter the predicted profile of breakdown products. To this end, including the relative sizes of enzymes would provide a better understanding of steric effects involved during enzyme diffusion and access to target bonds.

An assumption in the model is that an oligosaccharide was considered to be a breakdown product if it had a DP of six or fewer glycosyl residues (and, in the case of GAX, if it were not ester linked by diferulic acid to another oligosaccharide of DP 6 or greater). At each iteration, oligosaccharides identified as breakdown products would have a small probability (decreasing with DP) of being removed from the simulation but would otherwise remain in the simulation with the potential for being further degraded. This algorithm was intended to mimic the time taken for breakdown products to diffuse out of the cell wall matrix. Modelling a random walk for breakdown products may result in different profiles for breakdown products and relative activities of enzymes, but would require considerably increased computational power.

Our modelling of a perennial ryegrass primary cell wall used tethered network models of these walls. Our model can be used to explore alternative theories on the architecture of such walls, and indeed, the development of the model raised these issues as important considerations when simulating enzymatic action. Additionally, in order to represent a mesophyll cell wall of perennial ryegrass, we used few molecules of pectin, xyloglucans and $(1,3 ; 1,4)-\beta$-glucans. By varying the proportions of pectins and the different types of hemicelluloses, we can tailor the model to represent different wall types in different groups of plants, such as forage legumes. Our model represents primary cell walls that predominate in immature, leafy forage plants. However, by including lignin, we could extend the applicability of the model to lignified secondary walls that predominate in forages with mature flowering stems. Moreover, the part of the cell wall we have modelled is significantly smaller than a bacterial cell, and thus it would be desirable to considerably expand the size of our representation in terms of the length and number of CMFs, and concomitantly the proportions of other polysaccharides. 
Such extensions would dramatically increase the computational power needed to run the model. When graphics rendering is turned off, the time needed for collision detection appears to be the limiting factor governing the execution speed of the model and, since this is implemented using an OctTree, computational requirements are likely to show between linear and quadratic scaling with the size of the problem. Future work is likely to involve parallelising the code to allow it to be run on a cluster.

Ultimately we wish to extend this model by incorporating a representation of a biofilm attached to the PCW. This would then allow us to model the diffusion of detached structural agents through the plant polymer matrix to the biofilm, where they can interact with microbial agents and influence their growth and gene expression.

\section{Conclusions}

Our mesoscale model provides a number of advancements in the study of cell-wall degradation. It provides (to our knowledge) the first computer simulation in which cellulose, hemicelluloses and pectin are linked together to model the polysaccharide networks found in a specific type of PCW. It also provides a novel capability to study the enzymatic degradation of cell walls, by modelling the enzymes involved in cell-wall degradation, their diffusion, and their interaction with the polysaccharide networks at both the steric and catalytic level, and predicting the range of breakdown products.

The model can be applied to the study of enzymatic degradation of cell walls in a number of environments. These include industrial fermentation systems such as bioreactors and microbial ecosystems such as the rumen, composts and litters, and sludge. The capacity to simulate enzymatic action could be used to explore modification of PCWs by endogenous enzymes. An important potential application in this context is ripening of fruit, which involves a range of enzymes [75] including the pectin-degrading polygalacturonase [76,77] and could be invaluably explored in the context of an in silico model.

The 3-D representation of a primary perennial ryegrass cell wall provided by the model can be sequentially manipulated and modified, and provides an opportunity to explore different models of primary and secondary cell-wall architecture and hypotheses of how cell-wall components are linked. Thus the model has potential application in the area of plant physiology, particularly the study of the conformation of polymers comprising PCWs.

\section{Acknowledgments}

The authors are grateful to Roger Hellens, Hilary Ireland, Peter Janssen, Simon Lovatt, Paul Maclean, Alan McCulloch and Mike Tavendale for helpful advice and useful discussions. This work was funded by the Ministry of Business, Innovation \& Employment (NZ), NERF contract C10X0803.

\section{Conflicts of Interest}

The authors declare no conflict of interest. 


\section{References}

1. Edwards, J.E.; Huws, S.A.; Kim, E.J.; Lee, M.R.F.; Kingston-Smith, A.H.; Scollan, N.D. Advances in microbial ecosystem concepts and their consequences for ruminant agriculture. Animal 2008, 2, 653-660.

2. Hungate, R.E. The Rumen and Its Microbes; Academic Press: New York, NY, USA, 1966.

3. Krause, D.O.; Denman, S.E.; Mackie, R.I.; Morrison, M.; Rae, A.L.; Attwood, G.T.; McSweeney, C.S. Opportunities to improve fiber degradation in the rumen: Microbiology, ecology, and genomics. FEMS Microbiol. Rev. 2003, 27, 663-693.

4. Bacic, A.; Harris, P.J.; Stone, B.A. Structure and function of plant cell walls. In The Biochemistry of Plants. A Comprehensive Treatise; Preiss, J., Ed.; Academic Press: New York, NY, USA, 1988; Volume 14, pp. 297-372.

5. Harris, P.J. Non-cellulosic polysaccharides in plant cell walls: Their diversity, organization and approaches to understanding their functions. In The Hemicelluloses Workshop, The Wood Technology Research Centre, University of Canterbury, Christchurch, New Zealand, 2005; pp. 13-35.

6. Harris, P.J.; Stone, B.A. Chemistry and molecular organization of plant cell walls. In Biomass Recalcitrance: Deconstructing the Plant Cell Wall for Bioenergy; Himmel, M.E., Ed.; Blackwell Publishing Ltd.: Oxford, UK, 2008; pp. 61-93.

7. Vanholme, R.; Demedts, B.; Morreel, K.; Ralph, J.; Boerjan, W. Lignin biosynthesis and structure. Plant Physiol. 2010, 153, 895-905.

8. Jørgensen, H.; Kristensen, J.B.; Felby, C. Enzymatic conversion of lignocellulose into fermentable sugars: Challenges and opportunities. Biofuels Bioprod. Biorefining 2007, 1, 119-134.

9. Carpita, N.C.; Gibeaut, D.M. Structural models of primary cell walls in flowering plants: Consistency of molecular structure with the physical properties of the walls during growth. Plant J. 1993, 3, 1-30.

10. Cosgrove, D.J. Growth of the plant cell wall. Nat. Rev. Mol. Cell Biol. 2005, 6, 850-861.

11. Ding, S.-Y.; Himmel, M.E. The maize primary cell wall microfibril: A new model derived from direct visualization. J. Agric. Food Chem. 2006, 54, 597-606.

12. Harris, P.J. Diversity in plant cell walls. In Plant Diversity and Evolution: Genotypic and Phenotypic Variation in Higher Plants; Henry, R.J., Ed.; CAB International Publishing: Wallingford, Oxon, UK, 2005; pp. 201-227.

13. Fincher, G.B. Exploring the evolution of $(1,3 ; 1,4)-\beta$-D-glucans in plant cell walls: Comparative genomics can help! Curr. Opin. Plant Biol. 2009, 12, 140-147.

14. Harris, P.J.; Fincher, G.B. Distribution, fine structure and function of $(1,3 ; 1,4)-\beta$-glucans in the grasses and other taxa. In Chemistry, Biochemistry, and Biology of $(1 \rightarrow 3)-\beta$-Glucans and Related Polysaccharides; Bacic, A., Fincher, G.B., Stone, B.A., Eds.; Academic Press: San Diego, CA, USA, 2009; pp. 621-654.

15. Carpita, N.C.; Defernez, M.; Findlay, K.; Wells, B.; Shoue, D.A.; Catchpole, G.; Wilson, R.H.; McCann, M.C. Cell wall architecture of the elongating maize coleoptile. Plant Physiol. 2001, 127, $551-565$. 
16. Bunzel, M. Chemistry and occurrence of hydroxycinnamate oligomers. Phytochem. Rev. 2010, 9 , 47-64.

17. Ralph, J.; Bunzel, M.; Marita, J.M.; Hatfield, R.D.; Lu, F.; Kim, H.; Schatz, P.F.; Grabber, J.H.; Steinhart, H. Peroxidase-dependent cross-linking reactions of $p$-hydroxycinnamates in plant cell walls. Phytochem. Rev. 2004, 3, 79-96.

18. Wei, H.; Xu, Q.; Taylor, L.E., II; Baker, J.O.; Tucker, M.P.; Ding, S.-Y. Natural paradigms of plant cell wall degradation. Curr. Opin. Biotechnol. 2009, 20, 330-338.

19. Mayorga, O.L.; Huws, S.A.; Kim, E.J.; Kingston-Smith, A.H.; Newbold, C.J.; Theodorou, M.K. The occurrence of biofilm communities in the rumen. In Biofilms: Coming of Age; Gilbert, P., Allison, D., Brading, M., Pratten, J., Spratt, D., Upton, M., Eds.; The Biofilm Club: Manchester, UK, 2007; pp. 119-130.

20. Chesson, A.; Forsberg, C.W. Polysaccharide degradation by rumen microorganisms. In The Rumen Microbial Ecosystem; Hobson, P.N., Stewart, C.S., Eds.; Chapman and Hall: London, UK, 1997; pp. 329-381.

21. Flint, H.J.; Bayer, E.A.; Rincon, M.T.; Lamed, R.; White, B.A. Polysaccharide utilization by gut bacteria: Potential for new insights from genomic analysis. Nat. Rev. Microbiol. 2008, 6, 121-131.

22. Morrison, M.; Pope, P.B.; Denman, S.E.; McSweeney, C.S. Plant biomass degradation by gut microbiomes: More of the same or something new? Curr. Opin. Biotechnol. 2009, 20, 358-363.

23. Selinger, L.B.; Forsberg, C.W.; Cheng, K.J. The rumen: A unique source of enzymes for enhancing livestock production. Anaerobe 1996, 2, 263-284.

24. Wilson, D.B. Three microbial strategies for plant cell wall degradation. Ann. N. Y. Acad. Sci. 2008, 1125, 289-297.

25. Bannink, A.; de Visser, H.; van Vuuren, A.M. Comparison and evaluation of mechanistic rumen models. Br. J. Nutr. 1997, 78, 563-581.

26. Dijkstra, J.; France, J. A comparative evaluation of models of whole rumen function. Ann. Zootech. 1996, 45, 175-192.

27. Dijkstra, J.; Kebreab, E.; Mills, J.A.N.; Pellikaan, W.F.; Lopez, S.; Bannink, A.; France, J. Predicting the profile of nutrients available for absorption: From nutrient requirement to animal response and environmental impact. Anim. Feed Sci. Technol. 2007, 1, 99-111.

28. Offner, A.; Sauvant, D. Comparative evaluation of the Molly, CNCPS and LES rumen models. Anim. Feed Sci. Technol. 2004, 112, 107-130.

29. Levine, S.E.; Fox, J.M.; Blanch, H.W.; Clark, D.S. A mechanistic model of the enzymatic hydrolysis of cellulose. Biotechnol. Bioeng. 2010, 107, 37-51.

30. Hosseini, S.A.; Shah, N. Modelling enzymatic hydrolysis of cellulose part I: Population balance modelling of hydrolysis by endoglucanase. Biomass Bioenergy 2011, 35, 3841-3848.

31. Ye, Z.; Berson, R.E. Kinetic modeling of cellulosehydrolysis with first order inactivation of adsorbed cellulase. Bioresour. Technol. 2011, 102, 11194-11199.

32. Khodaverdi, M.; Jeihanipour, A.; Karimi, K.; Taherzadeh, M.J. Kinetic modeling of rapid enzymatic hydrolysis of crystalline cellulose after pretreatment by NMMO. J. Ind. Microbiol. Biotechnol. 2012, 39, 429-438. 
33. Griggs, A.J.; Stickel, J.J. A mechanistic model for enzymatic saccharification of cellulose using continuous distribution kinetics I: Depolymerization by EGI and CBHI. Biotechnol. Bioeng. 2012, 109, 665-675.

34. Griggs, A.J.; Stickel, J.J. A mechanistic model for enzymatic saccharification of cellulose using continuous distribution kinetics II: Cooperative enzyme action, solution kinetics, and product inhibition. Biotechnol. Bioeng. 2012, 109, 676-685.

35. Zhang, Y.-H.P.; Lynd, L.R. Towards an aggregated understanding of enzymatic hydrolysis of cellulose: Noncomplexed cellulase systems. Biotechnol. Bioeng. 2004, 88, 797-824.

36. Andronico, A.; Randall, A.; Benz, R.W.; Baldi, P. Data-driven high-throughput prediction of the 3-D structure of small molecules: Review and progress. J. Chem. Inf. Model. 2011, 51, 760-776.

37. Klepeis, J.L.; Lindorff-Larsen, K.; Dror, R.O.; Shaw, D.E. Long-timescale molecular dynamics simulations of protein structure and function. Curr. Opin. Struct. Biol. 2009, 19, 120-127.

38. Scheraga, H.A.; Khalili, M.; Liwo, A. Overview of molecular simulation techniques. Annu. Rev. Phys. Chem. 2007, 58, 57-83.

39. Stansfeld, P.J.; Sansom, M.S.P. Molecular simulation approaches to membrane proteins. Structure 2011, 19, 1562-1572.

40. Woodley, S.M.; Catlow, R. Crystal structure prediction from first principles. Nat. Mater. 2008, 7 , 937-946.

41. Sangha, A.K.; Petridis, L.; Smith, J.C.; Ziebell, A.; Parks, J.M. Molecular simulation as a tool for studying lignin. Environ. Prog. Sustain. Energy 2012, 31, 47-54.

42. Baird, M.S.; O’Sullivan, A.C.; Banks, W.B. A native cellulose microfibril model. Cellulose 1998, 5, 89-111.

43. Baird, M.S.; Hamlin, J.D.; O’Sullivan, A.; Whiting, A. An insight into the mechanism of the cellulose dyeing process: Molecular modelling and simulations of cellulose and its interactions with water, urea, aromatic azo-dyes and aryl ammonium compounds. Dyes Pigments 2008, 76, 406-416.

44. Bellesia, G.; Asztalos, A.; Shen, T.; Langan, P.; Redondo, A.; Gnanakaran, S. In silico studies of crystalline cellulose and its degradation by enzymes. Acta Crystallogr. 2010, D66, 1184-1188.

45. Beckham, G.T.; Bomble, Y.J.; Bayer, E.A.; Himmel, M.E.; Crowley, M.F. Applications of computational science for understanding enzymatic deconstruction of cellulose. Curr. Opin. Biotechnol. 2011, 22, 231-238.

46. Warden, A.C.; Little, B.A.; Haritos, V.S. A cellular automaton model of crystalline cellulose hydrolysis by cellulases. Biotechnol. Biofuels 2011, 4, 39.

47. Asztalos, A.; Daniels, M.; Sethi, A.; Shen, T.; Langan, P.; Redondo, A.; Gnanakaran, S. A coarse-grained model for synergistic action of multiple enzymes on cellulose. Biotechnol. Biofuels 2012, 5, 55.

48. Kha, H.; Tuble, S.C.; Kalyanasundaram, S.; Williamson, R.E. Wallgen, software to construct layered cellulose-hemicellulose networks and predict their small deformation mechanics. Plant Physiol. 2012, 152, 774-786.

49. Yi, H.; Puri, V.M. Architecture-based multiscale computational modeling of plant cell wall mechanics to examine the hydrogen-bonding hypothesis of the cell wall network structure model. Plant Physiol. 2012, 160, 1281-1292. 
50. Macall, C.M.; North, M.J. Tutorial on agent-based modelling and simulation. J. Simul. 2010, 4, $151-162$.

51. Niazi, M.; Hussain, A. Agent-based computing from multi-agent systems to agent-based models: A visual survey. Scientometrics 2011, 89, 479-499.

52. Hellweger, F.L.; Bucci, V. A bunch of tiny individuals-Individual-based modeling for microbes. Ecol. Model. 2009, 220, 8-22.

53. Xavier, J.B.; Picioreanu, C.; van Loosdrecht, M.C.M. A framework for multidimensional modelling of activity and structure of multispecies biofilms. Environ. Microbiol. 2005, 7, 1085-1103.

54. Baldazzi, V.; Castiglione, F.; Bernaschi, M. An enhanced agent based model of the immune system response. Cell. Immunol. 2006, 244, 77-79.

55. Davies, R. Documentation for Newmat11, a Matrix Library in C++; Statistics Research Associates Limited: Wellington, New Zealand, 2008.

56. FreeGLUT. The free opengl utility toolkit. Available online: http://freeglut.sourceforge.net/ (accessed on 12 April 2012).

57. Teschner, M.; Kimmerle, S.; Heidelberger, B.; Zachmann, G.; Raghupathi, L.; Fuhrmann, A.; Cani, M.-P.; Faure, F.; Magnenat-Thalmann, N.; Strasser, W.; et al. Collision detection for deformable objects. Comput. Graph. Forum 2005, 24, 61-81.

58. Lucchesis, B.J. A parallel linear octree collision algorithm. M.Sc. Thesis, University of Nevada, Reno, NV, USA, 2002.

59. Jacobs, W. Opengl tutorial. Lesson 10: Collision detection. Available online: http://www.videotutorialsrock.com/opengl_tutorial/collision_detection/home.php (accessed on 23 March 2011).

60. Chesson, A.; Gordon, A.H.; Lomax, J.A. Methylation analysis of mesophyll, epidermis, and fibre cell-walls isolated from the leaves of perennial and Italian ryegrass. Carbohydr. Res. 1985, 141, 137-147.

61. Chesson, A.; Gordon, A.H.; Scobbie, L. Pectic polysaccharides of mesophyll cell walls of perennial ryegrass leaves. Phytochemistry 1995, 38, 579-583.

62. Gordon, A.H.; Lomax, J.A.; Dalgarno, K.; Chesson, A. Preparation and composition of mesophyll, epidermis and fibre cell walls from leaves of perennial ryegrass (Lolium perenne) and Italian ryegrass (Lolium multiforum). J. Sci. Food Agric. 1985, 36, 509-519.

63. Smith, B.G.; Harris, P.J.; Melton, L.D.; Newman, R.H. Crystalline cellulose in hydrated primary cell walls of three monocotyledons and one dicotyledon. Plant Cell Physiol. 1998, 39, 711-720.

64. Newman, R.H.; Hill, S.J.; Harris, P.J. Wide-angle X-ray scattering and solid-state nuclear magnetic resonance data combined to test models for cellulose microfibrils in mung bean cell walls. Plant Physiol. 2013, 163, 1558-1567.

65. Xu, P.; Donaldson, L.A.; Gergely, Z.R.; Staehelin, L.A. Dual-axis electron tomography: A new approach for investigating the spatial organization of wood cellulose microfibrils. Wood Sci. Technol. 2007, 41, 101-116.

66. Paavilainen, S.; Róg, T.; Vattulainen, I. Analysis of twisting of cellulose nanofibrils in atomistic molecular dynamics simulations. J. Phys. Chem. B 2011, 115, 3747-3755. 
67. Ciesielski, P.N.; Matthews, J.F.; Tucker, M.P.; Beckham, G.T.; Crowley, M.F.; Himmel, M.E.; Donohoe, B.S. 3D electron tomography of pretreated biomass informs atomic modeling of cellulose microfibrils. ACS Nano 2013, 7, 8011-8019.

68. French, A.D.; Johnson, G.P. Cellulose and the twofold screw axis: Modeling and experimental arguments. Cellulose 2009, 16, 959-973.

69. Qi, M.; Jun, H.S.; Forsberg, C.W. Ce19d, an atypical 1,4- $\beta$-D-glucan glucohydrolase from Fibrobacter succinogenes: Characteristics, catalytic residues, and synergistic interactions with other cellulases. J. Bacteriol. 2008, 190, 1976-1984.

70. Qi, M.; Jun, H.S.; Forsberg, C.W. Characterization and synergistic interactions of Fibrobacter succinogenes glycoside hydrolases. Appl. Environ. Microbiol. 2007, 73, 6098-6105.

71. Matte, A.; Forsberg, C.W. Purification, characterization, and mode of action of endoxylanases 1 and 2 from Fibrobacter succinogenes S85. Appl. Environ. Microbiol. 1992, 58, 157-168.

72. Forano, E.; Delort, A.-M.; Matulova, M. Carbohydrate metabolism in Fibrobacter succinogenes: What NMR tells us. Microb. Ecol. Health Dis. 2008, 20, 94-102.

73. Hespell, R.B.; Wolf, R.; Bothast, R.J. Fermentation of xylans by Butyrivibrio fibrisolvens and other ruminal bacteria. Appl. Environ. Microbiol. 1987, 53, 2849-2853.

74. Kelly, W.J.; Leahy, S.C.; Altermann, E.; Yeoman, C.J.; Dunne, J.C.; Kong, Z.; Pacheco, D.M.; Li, D.; Noel, S.J.; Moon, C.D.; et al. The glycobiome of the rumen bacterium Butyrivibrio proteoclasticus $\mathrm{B} 316^{\mathrm{T}}$ highlights adaptation to a polysaccharide-rich environment. PLoS One 2010, 5, e11942.

75. Brummell, D.A. Cell wall disassembly in ripening fruit. Funct. Plant Biol. 2006, 33, 103-119.

76. Johnston, J.W.; Gunaseelan, K.; Pidakala, P.; Wang, M.; Schaffer, R.J. Co-ordination of early and late ripening events in apples is regulated through differential sensitivities to ethylene. J. Exp. Bot. 2009, 60, 2689-2699.

77. Tacken, E.; Ireland, H.; Gunaseelan, K.; Karunairetnam, S.; Wang, D.; Schultz, K.; Bowen, J.; Atkinson, R.G.; Johnston, J.W.; Putterill, J.; et al. The role of ethylene and cold temperature in the regulation of the apple polygalacturonase 1 gene and fruit softening. Plant Physiol. 2010, 153, 294-305.

(C) 2014 by the authors; licensee MDPI, Basel, Switzerland. This article is an open access article distributed under the terms and conditions of the Creative Commons Attribution license (http://creativecommons.org/licenses/by/3.0/). 